\title{
P02.133. Randomized double blinded clinical trial of Ojeoksan products extracted through different methods for low back pain
}

\author{
S Lee*, J Lee \\ From International Research Congress on Integrative Medicine and Health 2012 \\ Portland, Oregon, USA. 15-18 May 2012
}

\section{Purpose}

The aim of the present study is to observe the efficacy of Ojeoksan and the difference in the results induced by extracting methods among mixtures of independently extracted herbs (MIE group), extract from combined decoction (ECD group) and placebo (Placebo group).

\section{Methods}

The study was approved by the Ethics Committee of Kyunghee Oriental Medical Center in Seoul, Korea. Sixty subjects ( $M: F=26: 34)$ with low back pain were recruited in the study and randomly allocated to MIE group, ECD group and Placebo group. During 4 weeks, the MIE group took the Ojeoksan Mixture of Independently Extracted Herbs, the ECD group took the Ojeoksan Extract from combined Decoction, and the Placebo group took a placebo. The effect of Ojeoksan on pain was measured with VAS (Visual Analogue Scale) and SF-36 Bodily Pain scale. Disability was measured with RMDQ (Roland-Morris Disability Questionnaire). General health was measured with the SF-36 (36-Item Short-Form Quality of Life Questionnaire) and range of motion was measured with MMST (Modified-Modified Schober Test) at baseline, 2 weeks and 4 weeks. Efficacy was evaluated with the SPSS 12.0 paired t-test for intragroup testing and ANCOVA (Analysis of covariance) for intergroup testing.

\section{Results}

After 4 weeks, the MIE group showed significant improvement on VAS, RMDQ and MMST; the ECD group showed significant improvement on VAS, SF-36 Bodiliy Pain scale, RMDQ, SF-36 and MMST; the Placebo group

Kyunghee University, Daejeon, Republic of Korea showed significant improvement on VAS and MMST by paired t-test. In RMDQ, each group showed a significant difference, but other scales showed no difference analysed by ANCOVA.

\section{Conclusion}

According to the results, Ojeoksan is more efficacious on pain, disability and general health for low back pain patients than placebo. Ojeoksan extract from combined decoction is more efficacious than Ojeoksan mixture of independently extracted herbs and placebo on disability caused by lumbar back pain.

Published: 12 June 2012

doi:10.1186/1472-6882-12-S1-P189

Cite this article as: Lee and Lee: P02.133. Randomized double blinded clinical trial of Ojeoksan products extracted through different methods for low back pain. BMC Complementary and Alternative Medicine 201212 (Suppl 1):P189.

Submit your next manuscript to BioMed Central and take full advantage of:

- Convenient online submission

- Thorough peer review

- No space constraints or color figure charges

- Immediate publication on acceptance

- Inclusion in PubMed, CAS, Scopus and Google Scholar

- Research which is freely available for redistribution

(c) 2012 Lee and Lee; licensee BioMed Central Ltd. This is an Open Access article distributed under the terms of the Creative Commons 